\title{
A Filosofia da informação e a Sociedade da informação e do conhecimento: reflexões diante do progresso tecnológico
}

\author{
Philosophy of information and the Information Society: reflections in the face of the \\ technological context
}

Késsia Rita da Costa Marchi Doutoranda no Programa de Pós-Graduação em Ciência da Informação pela Universidade Estadual Paulista UNESP, campus de Marília. Brasil. Docente Ensino Básico, Técnico e Tecnológico do Instituto Federal do Paraná - campus Paranavaí, Brasil.

E-mail: kessia.marchi@unesp.br https://orcid.org/0000-0001-5504-5685

Marta Lígia Pomim Valentim Livre Docente em Informação, Conhecimento e Inteligência Organizacional Universidade Estadual Paulista -

Unesp, campus de Marília, Brasil. Professora Titular da Universidade Estadual Paulista - Unesp, campus de Marília, Brasil.

E-mail: marta.valentim@unesp.br https://orcid.org/0000-0003-4248-5934

\begin{abstract}
Leonardo Castro Botega Doutor em Ciência da Computação pela Universidade Federal de São Carlos - UFSCar, Brasil. Membro Permanente do Programa de Pós-graduação em Ciência da Informação da Universidade Estadual Paulista - Unesp, campus de Marília, Brasil.

E-mail: leonardo.botega@unesp.br https://orcid.org/0000-0003-1495-5935
\end{abstract}

\section{Resumo}

As tecnologias de informação e comunicação tem alterado a vida cotidiana e transformado o conceito 'informação' em um conceito interdisciplinar, presente em diversos domínios e que desempenha um papel central na sociedade contemporânea. Nesse contexto, surge o campo científico denominado 'Filosofia da Informação' como uma nova proposta de investigação para a geração de conhecimento teórico, tendo como base e enfoque a informação, assim como a elaboração de metodologias informacionais e computacionais e a aplicação destas a problemas filosóficos. Diante disso, apresenta-se uma revisão de literatura inicial que busca destacar o panorama da Filosofia da Informação e a sua relação com a Sociedade da Informação e do Conhecimento, procurando contribuir para uma melhor compreensão deste campo neste cenário social e tecnológico. Observou-se que a Filosofia da Informação tem se consolidado como um campo de investigação autônomo que versa sobre questões emergentes da Sociedade da Informação e do Conhecimento e, assim, desperta a necessidade de reflexões sobre como a sociedade se comporta diante do progresso tecnológico. Discussões tem ocorrido de modo crescente no âmbito da área da Ciência da Informação, sendo esta apresentada como uma área promissora e com relatos sobre sua importância, entretanto ainda há lacunas a serem estudadas e respondidas.

Palavras-Chave: Filosofia da Informação. Sociedade da Informação. Tecnologia de Informação e Comunicação. Informação Tecnológica. 


\begin{abstract}
Information and communication technologies have changed life every day and transformed the concept 'information' into an interdisciplinary concept, present in several domains and which plays a significant role in contemporary society. In this context, the scientific field called 'Philosophy of Information' appears as a new research proposal for the generation of theoretical knowledge, based on and focusing on information, as well as the elaboration of informational and computational methodologies and their application to philosophical problems. In view of this, an initial literature review presented that seeks to highlight the panorama of the Philosophy of Information and its relationship with the Information and Knowledge Society, seeking to contribute to a better understanding of this field in this social and technological context. It observed that the Philosophy of Information has consolidated itself as a field of autonomous investigation that deals with emergent issues of the Information and Knowledge Society and, thus, arouses the need for reflections on how society behaves in the face of technological progress. Discussions have taken place increasingly in the scope of the Information Science area, which presented as a promising area and with reports on its importance, however there are still gaps to be studied and answered.
\end{abstract}

Keywords: Philosophy of Information. Information Society. Information and Communication Technology.

\title{
1. Introdução
}

A demasiada e facilitada produção de informação, sobretudo por meio de recursos tecnológicos utilizados nas últimas décadas tem proporcionado algumas inquietações acerca do pensamento filosófico inter-relacionado à informação e à Sociedade da Informação, visto que a informação tem desempenhado um papel central na sociedade contemporânea e é considerada como condição básica para o desenvolvimento econômico e social (CAPURRO; HJØRLAND, 2007).

O impacto das novas Tecnologias de Informação e Comunicação (TIC) na vida cotidiana influi significativamente na noção do que é informação, cujo conceito se modifica de disciplina para disciplina ou de contexto para contexto. Saracevic (1975) ressaltou que em uma disposição formal o fenômeno informação é estudado em disciplinas diversas e apresenta ramificações complexas e muitas manifestações associadas a ela.

Para Barreto (2003) a informação passou a ser compreendida como um produto ou uma mercadoria e esta alteração levou a necessidade de pensar sobre o fluxo informacional e buscar compreender a qualidade deste produto. $\mathrm{O}$ autor ressalta que a informação é considerada como uma mercadoria simbólica de características específicas que não se esgota com o consumo e ao ser consumida permanece consumível por um tempo determinado em um espaço definido e estas características determinam sua qualidade e validade. 
Outras características evidenciadas por Barreto (2003) se referem que a informação ao ser consumida não transmite a propriedade, isto é, ela continua como posse de quem a detém, salvo em casos muito especiais. A sua unidade de medida é imprecisa e não é homogênea e o seu preço, caso possua, tem pouco a ver com o seu custo, bem como não há relação entre o valor de custo e o valor de venda e, muito menos, com o valor atribuído pelo sujeito que a utiliza e, por último, com as condições de oferta e demanda de mercado.

No contexto pós-moderno, a informação e o conhecimento se constituem por uma aparente via de ruptura, que faz surgir revoluções científicas, estabelecem abertura para relações disciplinares, fornece subsídios para o desenvolvimento de teorias, metodologias e filosofia acerca da informação e da informação tecnológica que para Ilharco (2003) são consideradas uma fonte de poder.

É neste aspecto que Floridi (2002) apresenta um caminho diferente e interessante ao propor o campo da Filosofia da Informação. Entre as questões afetas à esta filosofia, algumas reflexões são objetos de estudo, entre elas o que vem a ser filosofia da informação? E qual a sua relação com a Sociedade da Informação?

Floridi (2002) estabelece estes questionamentos e apresenta a proposta de um pensar filosófico sobre a informação. Para este autor, pensar filosoficamente parte de uma lógica computacional, na qual as teorias semânticas, matemáticas e comunicacionais se apresentam como fundamentos para a sua análise. Ilharco (2003), tendo como base os trabalhos de Floridi, compreende a Filosofia da Informação como uma nova área de investigação e de conhecimento, cujo objetos de estudos se referem a investigação crítica da natureza conceitual e dos princípios de base da informação, assim como a elaboração de metodologias teóricas informacionais e computacionais e a aplicação destas a problemas filosóficos.

Com base no âmbito da Sociedade da Informação, propõe-se buscar compreender a filosofia da informação e sua relação com a sociedade contemporânea. Esta revisão de literatura inicial contempla discussões acerca da informação, da filosofia da informação, da informação tecnológica e da Sociedade da Informação, no intuito de contribuir para um melhor entendimento sobre o campo da Filosofia da Informação no contexto desta sociedade.

Para tanto, foi desenvolvido uma revisão de literatura, a partir de uma abordagem introdutória, cujos referenciais teóricos analisados versam sobre a informação, a Filosofia da Informação e a Sociedade da Informação. Esta pesquisa se caracteriza como descritiva- 
exploratória, por buscar descrever conceitos e fatos, visando melhor compreender a temática abordada. Na busca por artigos, teses e dissertações que tratam dessas temáticas, pesquisou-se nas seguintes fontes de informação: Base de Dados Referenciais de Artigos de Periódicos em Ciência da Informação (BRAPCI), Repositório dos Encontros Nacionais de Pesquisa e PósGraduação em Ciência da Informação (BENANCIB), The Scientific Electronic Library Online (SciELO) e The Institute of Electrical and Electronics Engineers (IEEE).

\section{Filosofia da informação}

Na sociedade contemporânea, também denominada de Sociedade da Informação, as atividades relacionadas a informação e ao conhecimento ganharam grande valor e importância. A informação, o conhecimento e a competência em informação são pilares que sustentam o desenvolvimento da civilização, sendo a primeira um relevante elemento para o entendimento da realidade. Quando os fragmentos de informações são unidos e harmonizados, formam uma base de sustentação que possibilitam iniciativas inovadoras e a geração de novos conhecimentos (BOTTENTUIT JÚNIOR; COUTINHO, 2007; VIEIRA, 2006).

A facilidade de produzir e comunicar informações, por meio de aparatos tecnológicos, gerou algumas inquietações no que diz respeito ao pensamento filosófico da informação. E a informação, por sua vez, ganhou novas formas de análise em relação a sua produção, propagação e inserção social, passando a ser estudada como uma abordagem reflexiva, embasada na Ciência da Informação e na própria Filosofia (SALCEDO; REVOREDO, 2013).

Neste cenário de emergência de um novo tipo de informação que, de acordo com Ilharco (2003), se refere a uma informação gerada, gerida, manipulada, armazenada e distribuída pela tecnologia, surge a Filosofia da Informação como um paradigma que visa descrever e entender a relação do homem com a informação tecnológica e, de acordo com Leite (2018), busca uma retomada de seus princípios epistemológicos.

Floridi (2004), filósofo italiano que cunhou a expressão 'Filosofia da Informação', a compreende como uma área de pesquisa filosófica preocupada com a investigação crítica da estrutura conceitual e dos princípios básicos da informação, bem como no que tange a elaboração e aplicação de teorias e metodologias informacionais e computacionais relacionadas aos problemas filosóficos (SALCEDO; REVOREDO, 2013). 
Cabe ressaltar que embora o termo Filosofia da Informação seja apresentado como uma formulação original por Floridi, as discussões sobre este tema já existiam anteriormente a este pesquisador, principalmente nos trabalhos de Norbert Wiener, Claude Shannon, Warren Weaver, Fred Dretske e Terrence Deacon (RIPOLL; MATOS, 2020).

O campo da Filosofia da Informação nasceu da Filosofia da Computação e possui uma área de investigação abrangente que está relacionada às preocupações da Sociedade da Informação. Capurro e Hjørland (2007) esclarecem que, embora a informação e a comunicação sejam fenômenos básicos, é a partir do surgimento das TIC e seus impactos globais que conformam a denominada Sociedade da Informação.

O objeto de estudo da Filosofia da Informação é alicerçado na informação tecnológica e nos instrumentos informacionais, considerando a vasta presença das TIC na sociedade contemporânea. À medida que novas tecnologias se inserem nas mais diversas áreas do saber e do fazer da sociedade hodierna, o fenômeno informação ganha relevância e destaque (ILHARCO, 2003; PELLEGRINI; VITORINO, 2018).

Autores como Ilharco (2003), Revoredo (2015) e Pellegrini e Vitorino (2018) evidenciam que questionar o que é informação denota a um conceito vago e evasivo, entretanto poderoso, uma vez que pode ser associado à diversas explanações dependendo dos requisitos e intenções. Corroborando com estes autores, Capurro e Hjørland (2007) analisam o termo informação como um conceito interdisciplinar e afirmam que este conceito está presente em diferentes domínios e é fluído, uma vez que sua natureza muda conforme a finalidade e contexto. Em contraponto a esses autores, Floridi (2017) afirma que o conceito informação, geralmente utilizado apenas como suporte para a investigação de outros conceitos, merece uma investigação filosófica autônoma e carece de força enquanto campo individual.

No domínio da Ciência da Informação, o conceito de informação é apresentado por Pellegrini e Vitorino (2018) no sentido de conhecimento comunicado que, quando extraída da mente por meio de linguagem natural, pode ser registrada, duplicada, transmitida, armazenada, organizada, processada, recuperada e reutilizada. Na esfera da Ciência da Computação, o conceito de informação refere-se ao resultado obtido por meio de processamento de dados.

A informação tecnológica, por sua vez, é definida por Ilharco (2003) como a matéria prima de distintas áreas do conhecimento e possibilita que novos desenvolvimentos e as próprias possibilidades de progresso sejam dependentes da capacidade de gerar novas 
tecnologias. Diante disso, Ilharco $(2003 ; 2005)$ também destaca que a Filosofia da Computação delineia o seu objeto na informação tecnológica e nos instrumentos informacionais. Por outro lado, a Filosofia da Informação privilegia a informação como seu tópico central, em detrimento da computação. As questões da computação são tratadas pela Filosofia da Informação apenas como um processo em que a informação está envolvida.

Nessa perspectiva, a Filosofia da Informação é considerada uma área relativamente nova, que se preocupa em analisar questões fundamentais relacionadas à informação enquanto conteúdo de interação social, cuja tarefa, apontada por Floridi (2002), está em desenvolver teorias integradas que permitam analisar, avaliar e explicar os diversos princípios da informação, assim como, sua dinâmica e utilização especialmente relacionadas a questões sistêmicas que emergem dos diversos ambientes de aplicação e interconexões com outros conceitos. Para Francelin e Pellegatti (2004) o desenvolvimento destas tarefas seguem métodos de estudos que se baseiam na complexidade do pensamento e do cotidiano humano.

Nesse sentido, Ilharco (2003) fundamentado nos conceitos proposto por Floridi (2002), apresenta inicialmente um conjunto de problemas que evidenciam grau de relevância distintos para a Filosofia da Informação. Estes problemas foram posteriormente abordados e refinados por Floridi (2011) e por Pellegrini e Vitorino (2018) e para este artigo são destacados (Figura 1) apenas os problemas e questionamentos que envolvem as TIC.

Figura 1 - Problemas da Filosofia da Informação

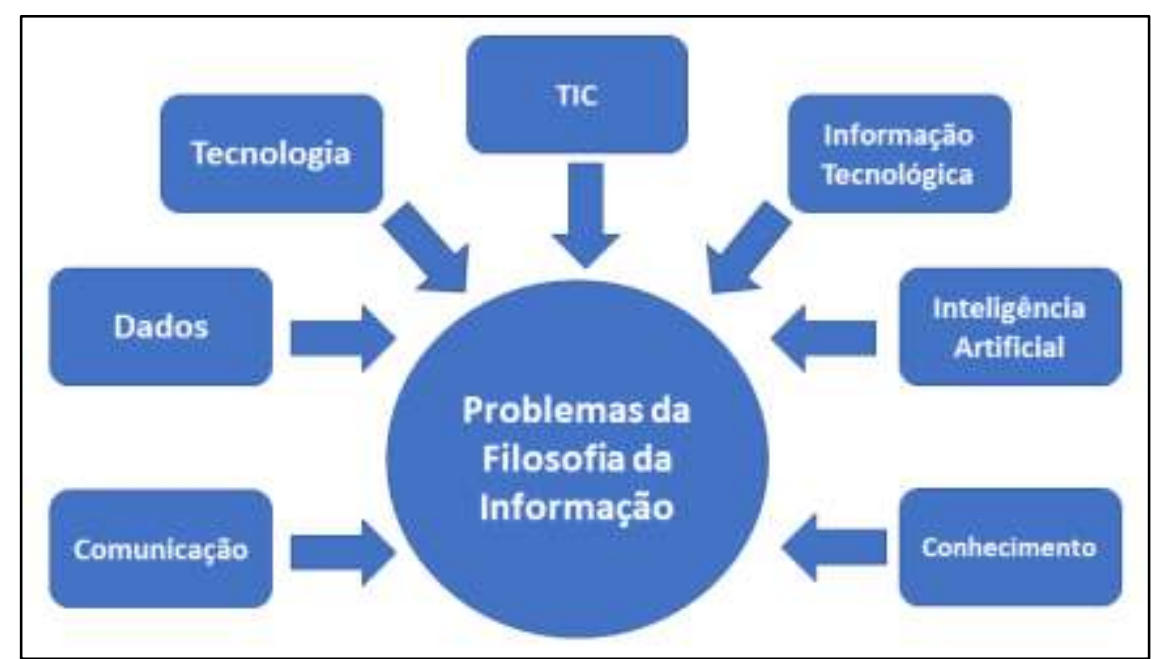

Fonte: Adaptado de Pellegrini e Vitorino (2018, p. 122).

- O problema da comunicação: O que é a comunicação? Informação e comunicação: qual fenômeno precede o outro? O que é comunicação sem informação? O que é informação sem comunicação? 
- O problema dos dados: O que são dados? O que distingue informação de dados? Como é possível constatar ou distinguir dado de informação?

- O problema da tecnologia em geral: Que relação existe entre a eficiência tecnológica e a informação? Será eficiente um processo de informação?

- O problema das TIC: O que é tecnologia da informação e comunicação? Qual o caráter tecnológico da informação? Qual o caráter tecnológico da comunicação? Como se juntam no mesmo fenômeno os fenômenos da tecnologia, informação e comunicação? Qual ou quais os critérios para classificar tecnologias, instrumentos, aparelhos etc. como TIC?

- A informação tecnológica como contexto: Para o autor não há clareza referente as implicações e consequências para as organizações e para a sociedade em geral que questione a pertinência da visão instrumental sobre a informação tecnológica como contexto.

- A problema da inteligência artificial: O que é inteligência artificial? Qual a relação da informação com a inteligência artificial? Qual a diferença entre inteligência artificial e conhecimento? Quais as dimensões humanas possíveis e impossíveis de serem replicadas? (ILHARCO, 2003).

Estas indagações permitiram definir o corpus da Filosofia da Informação, assim como, a sua metodologia de trabalho. Também permitiram que ela fosse entendida como uma nova etapa do processo de "semantização do ser", ou seja, uma forma atualizada e completa de compreender o mundo e a sociedade (LEITE, 2018; FLORIDI, 2002). Corroborando a isso, Francelin e Pelegatti (2004) apresentam a afirmação de que a Filosofia da Informação pode ser assimilada como um campo de estudo maduro. Os autores entendem que os processos de desenvolvimento filosófico que permitem melhor interpretar cultura e sociedade, contribuíram e continuam a contribuir para o desenvolvimento desta filosofia.

Diante das questões supracitadas, Floridi (2002) explica que a Filosofia da Informação procura expandir a fronteira da pesquisa filosófica, o que permite incluir novas áreas a sua investigação e proporcionar uma reordenação do cenário filosófico. Francelin e Pelegatti (2004) complementa que esta filosofia busca analisar os mais variados assuntos que estejam relacionados à Informação, dando menos ênfase as questões pertinentes as ferramentas e as 
operações que dão suporte a esta. Ilharco (2005), no que lhe concerne, revela que a Filosofia da Informação é um projeto destinado a consolidar uma nova área de investigação autônoma, com novas perspectivas de apropriação e disseminação da informação por parte da sociedade.

Para Salcedo e Revoredo (2013) a Filosofia da Informação observa a informação em seus diversos ambientes, admite a sua relação intrínseca com a sociedade e a considera como perspectiva de futuro, acompanhando a evolução das tecnologias de informação e comunicação. Os autores também consideram que esta área de estudo é voltada para investigações críticas da estrutura conceitual e das elaborações e aplicações da teoria da informação e de metodologias computacionais aplicados a problemas filosóficos.

Diante do exposto, é notória a relação inerente entre informação, informação tecnológica e o desenvolvimento da sociedade contemporânea, o que fez surgir e faz fortalecer o campo de estudo da Filosofia da Informação. Esta filosofia possui como objeto de estudo a informação considerando-a como fenômeno que está diretamente relacionada as TIC. Percebese também que as reflexões referentes aos elementos conceituais possuem uma vertente tecnológica alinhada aos processos sociais.

Ao considerar as definições de Filosofia da Informação apontadas e a afirmação de Ilharco (2003), na qual relata que, do ponto de vista estruturalista radical, a informação e o conhecimento são considerados uma fonte de poder, cujo seu domínio e acesso tem uma relação direta com a possibilidade de exercer e aumentar este poder. Nesse contexto, o autor argumenta "Como podem os excluídos, os explorados, os prejudicados informarem-se de modo a aumentar o seu poder e a alterar a sua situação?" Da mesma forma, ele indaga "Como podem os mais beneficiados, os dominantes, obter e controlar informação que lhes permita manter ou fortalecer a sua posição de domínio?”

Ainda, na conjuntura de atividade social, a informação é considerada um fenômeno entendido no âmbito do conflito estrutural entre os dominantes e os dominados e que a realidade experimentada por cada um, as habilidades desenvolvidas, os objetivos, os conhecimentos adquiridos e as experiências vivenciadas, formam a base de sustentação que possibilita ou impede quaisquer possibilidades. Estas argumentações estão intimamente relacionadas à influência e ao papel que a Ciência e a tecnologia têm desempenhado na sociedade contemporânea, sociedade esta que tem sido identificada na literatura como 'Sociedade da Informação'. 


\section{Sociedade da informação}

Para poder estabelecer a relação entre a Sociedade da Informação e a Filosofia da Informação é necessário compreender e avançar seu conceito. Freitas (2002) apresenta que este termo teve seu primeiro uso em 1970 na reunião anual realizada pela American Society for Information Science, que abordou o tema The Information Conscious Society, entretanto, o autor ainda cita que há estudiosos que atribuem o crédito pelo termo "Sociedade da Informação" aos japoneses Jiro Kamishima, em 1963, que utilizou este termo no artigo publicado no periódico Hoso Asahi, e Yujiro Hayashi em 1969 em dois relatórios e na publicação do livro The Information Society: from hard to soft.

Floridi (2010b) argumenta que as TIC promoveram uma nova organização da sociedade, levando-a a funcionar em torno de serviços e produtos informacionais. Corroborando a isto, Wilke (2012) apresenta a informação como elemento fundamental presente em construções ideológicas contemporâneas, legitimadas pelos modos atuais de produção e de controle social, mediadas por tecnologias de informação e comunicação.

Montoya-Mogollón e Madio (2018) enfatizam que a sociedade atual está permeada por recursos tecnológicos que começam a modificar o comportamento humano e propõem definições mais reais para conceituar a sociedade contemporânea, buscando exemplificar uma sociedade que realiza avanços tecnológicos significativos em serviços voltados à humanidade. Os relacionamentos presentes na vida contemporânea são elaborados a partir de processos comunicacionais e informacionais, nos quais a virtualidade se faz presente, fazendo surgir uma nova organização social.

Nessa circunstância, Ripoll e Mattos (2020), baseados nas definições de Floridi, afirmam que a Sociedade da Informação se refere ao meio caracterizado pelas ações cognitivas humanas, sendo o mundo físico apenas o pano de fundo do processo de desenvolvimento social, no qual o ser humano produz e emprega símbolos para transmitir informações e organizar sua vivência social e individual. No que tange ao fenômeno da Sociedade da Informação, os autores comentam que a informação deixa de ser apenas um meio para a obtenção de conhecimento e passa a ser o cerne da discussão acerca de tudo o que movimenta a sociedade. 
Salcedo e Revoredo (2013) comentam que a expressão 'Sociedade da Informação' substitui o conceito de 'Sociedade Pós-Industrial'. Leite e Matos (2017) também caracterizam a Sociedade da Informação por utilizar novas TIC e definir suas relações sociais e econômicas em torno do objeto informação. Ao buscar entender as diferenças entre a Sociedade Industrial e a Sociedade da Informação, Borges (2000) elaborou um texto comparativo (Quadro 1), que descreve as características das empresas em cada época.

Quadro 1 - Sociedade Industrial versus Sociedade da Informação

\begin{tabular}{|l|ll|}
\hline \multicolumn{1}{|c|}{ Empresas - Sociedade Industrial } & \multicolumn{3}{|c|}{ Empresas - Sociedade da Informação } \\
\hline Enfoque analítico / atomístico. & Enfoque macro / holístico. \\
\hline $\begin{array}{l}\text { Individualismo / predomínio / distanciamento } \\
\text { entre as pessoas. }\end{array}$ & $\begin{array}{l}\text { Igualdade de direitos / compartilhamento / } \\
\text { participação. }\end{array}$ \\
\hline $\begin{array}{l}\text { Autoridade centralizadora / paternalista / } \\
\text { autocrática. }\end{array}$ & Autoridade adulta / facilitadora / democrática. \\
\hline $\begin{array}{l}\text { Continuidade num único nicho profissional. } \\
\text { Especialização excessiva. }\end{array}$ & $\begin{array}{l}\text { Opções múltiplas. Liberdade de escolha. Visão } \\
\text { generalizada. }\end{array}$ \\
\hline $\begin{array}{l}\text { Economia de escala / tendência ao gigantismo e } \\
\text { à centralização. }\end{array}$ & \begin{tabular}{l} 
Descentralização, resguardando-se a integração. \\
\hline Valorização da quantidade.
\end{tabular} & $\begin{array}{l}\text { Valorização da qualidade associada à } \\
\text { quantidade. }\end{array}$ \\
\hline $\begin{array}{l}\text { Empresário avesso ao risco. Busca de } \\
\text { protecionismo. }\end{array}$ & $\begin{array}{l}\text { Empresário empreendedor, criativo e e } \\
\text { competitivo. }\end{array}$ \\
\hline A grande alavanca é o dinheiro. & $\begin{array}{l}\text { A grande alavanca é a informação/o } \\
\text { conhecimento / a educação. }\end{array}$ \\
\hline $\begin{array}{l}\text { O sucesso é garantido pelo poder de investimento } \\
\text { em máquinas e instalações. }\end{array}$ & $\begin{array}{l}\text { A mente humana é o grande software. O } \\
\text { computador é o grande hardware. }\end{array}$ \\
\hline
\end{tabular}

Fonte: Borges (2000, p. 29).

Ao analisar os aspectos evidenciados no Quadro 1, é possível observar que no cenário da Sociedade da Informação apresentado por Borges, a alavanca de desenvolvimento passa a ser o ser humano, sendo a informação e o conhecimento considerados como um produto, um bem comercial. Diante disso, é observado que as TIC têm seu papel fundamental nesta sociedade e converteram o mundo em uma aldeia global, alterando a distância e o tempo entre a fonte da informação e seu destinatário. Elas também criaram serviços, mercados, empregos e empresas e interferiram no ciclo informativo, em diversos pontos de vista, como dos processos, das atividades, da gestão, dos custos, das culturas, da educação, entre outros. Perante o exposto, Santos e Carvalho (2009) corroboram afirmando que esta sociedade produz mudanças em níveis fundamentais, alterando relações de trabalho, sociais e produção de bens e consumo.

Ilharco (2003) acentua que o nome atribuído a esta sociedade surge intuitiva e implicitamente sob o prisma da informação e das TIC, destacando o entendimento da maneira como a realidade das ações dos homens permeia o mundo e, assim, oferece abertura para um 
entendimento mais profundo da sociedade atual no domínio da metafísica. À vista disso o autor destaca:

\begin{abstract}
O domínio metafísico que a Sociedade da Informação detém hoje em dia no mundo contemporâneo revela-se sobretudo na forma como ele próprio não deixa se ver, por que sendo metafísico ele é a base, constituindo-se assim como critério, filtro, perspectiva ou background, através e âmbito do qual surge o que existe nos seus contornos de relevância, de materialidade, de intangibilidade, de significado de futuro (ILHARCO, 2003, p. 76).
\end{abstract}

A vasta presença das TIC na sociedade contemporânea estabelece um fenômeno permanente que é constituído no modo, meio e contexto da ação dos homens no mundo. A estrutura da informação é assentada em uma lógica essencialmente tecnológica, o que propicia que a informação esteja à vista e à mão, podendo ser utilizada nas mais diversas tarefas do cotidiano (ILHARCO, 2003; 2005).

Esse modelo de sociedade ressalta que as TIC desempenham um papel fundamental nas atividades cotidianas, conforme evidenciado no Quadro 1. As TIC possibilitam alterar a velocidade de transmissão da informação, ampliar as possibilidades de controle, armazenamento, utilização e reutilização da informação e facilitam o surgimento de novas formas de comunicação que, por sua vez, auxiliam o desenvolvimento da sociedade e proporciona suportes a formação de redes de comunicação a distância, de armazenamento e de processamento da informação, caracterizando assim, o envolvimento dos homens no mundo (BORGES, 2000; RODRIGUES, 2016).

Nessa perspectiva, destaca-se o trabalho de Montoya-Mogollón e Madio (2018) em que apresentam um debate acerca do conceito de 'Sociedade da Informação' e expõem reflexões sobre os conceitos de 'Sociedade Informacional' ou 'Sociedade da Tecnologia de Informação' não apenas como um dilema semântico, mas também como um dilema social. Ao considerar o livro ‘A Sociedade em Rede' de Manuel Castells, concluem que a Sociedade da Informação é distinta de Sociedade Informacional, evidenciando a relevância da informação como objeto de comunicação na sociedade e, concluem que o mundo se encontra mais perto de uma Sociedade Informacional mediada por tecnologias do que se compreende por Sociedade da Informação.

Considerando esta reorganização social, Ripoll e Matos (2020) afirmam que está ocorrendo uma nova organização do conhecimento, desenvolvida por meio das proposições de novas metodologias e reformulação da base ontológica e epistemológica. Barreto (2003) já destacava a existência da promessa de que o acesso à informação na Sociedade da Informação 
ocorreria a todos igualmente, entretanto, esta promessa não trouxe apenas premissas técnicas, mas uma série de fatores que permitem que o ser humano possa ir além de suas possibilidades. Desse modo, cabe ressaltar que as premissas técnicas se apresentam apenas no sentido da exploração, como arcabouço informacional. Para Cezar e Suaiden (2017) esta nova organização considera a revolução tecnológica e se faz responsável pela maior interação entre as pessoas e a sociedade, unificando o sistema produtivo e mercantil global, reestruturando assim, o capitalismo.

Em contraponto a estas afirmações, Roza (2018) argumenta que as TIC não são as únicas responsáveis pelas transformações sociais vivenciadas na Sociedade da Informação. Esta nova forma de sociedade é fruto de diversas mudanças sociais, econômicas, culturais e tecnológicas. Afirma, ainda, que as TIC beneficiam a sociedade em relação à informação, mas por outro lado contribuem para o surgimento de diversos problemas como a sobrecarga de informação e a falta de confiabilidade das informações produzidas e disseminadas.

No estágio atual de desenvolvimento da humanidade, a Filosofia da Informação se faz pertinente, uma vez que traz novas percepções e faz emergir questionamentos significativos, entre eles:

O que significa esse 'novo mundo' para as vidas humanas? Quais implicações, consequências, possibilidades e limites sugeridos, possíveis ou necessários, dado que se vive imerso em informação tecnológica? Até que ponto os traços essenciais daquilo que hoje representa o homem no mundo são desenhados, assentam ou dependem da tecnologia e da informação tecnológica? (ILHARCO, 2003, p.92).

A partir dos conteúdos abordados, autores como Ilharco (2003), Francelin e Pellegatti (2004), Salcedo e Revoredo (2013) e Rodrigues (2016), entre outros, propiciam reflexões significativas acerca da Sociedade da Informação no âmbito da Filosofia da Informação. O cerne dessas reflexões está na análise da dependência que as TIC causam ao indivíduo, assim como o quanto elas transformam a realidade vivenciada. 


\section{Filosofia da informação e a Sociedade da informação}

A Sociedade da Informação tem possibilitado novas maneiras de pensar e agir sobre as atividades humanas em relação a informação e ao conhecimento. Com base nessa premissa, Ilharco (2003) inicia essa reflexão afirmando que as sociedades contemporâneas mais avançadas, baseiam suas atividades e comunicações em informações geradas e gerida por tecnologias. Este desenvolvimento tem provocado alterações importantes nos aspectos socioeconômicos, políticos, ambientais, culturais, educacionais e comportamentais, levando o homem a ter que se adaptar a este contexto. Contudo, o autor afirma também que, naquele momento, não havia indícios que revelassem os efeitos, implicações e consequências da introdução e da apropriação das novas TIC na vida organizacional.

Cezar e Suaiden (2017), em face do exposto, contribui afirmando que os avanços tecnológicos geram impactos e mudanças em todos os aspectos da sociedade e tem se constituído como uma tendência dominante, considerando que o poder da informação perpassa a vida em sociedade e definem dinâmicas nas quais as práticas sociais e o espaço físico passam a ser reconfigurados a partir das TIC.

Ilharco (2003) ainda explana sobre o uso do computador e dos avanços tecnológicos vivenciados pela sociedade, destacando a entrada massiva das TIC nos anos de 1970. Nesta primeira fase de absorção, não havia qualquer processo de controle ou de coordenação, o que levava a decisões individuais e definia que a tecnologia, por si só, proporcionaria mudanças desejadas em termos de produtividade e de competitividade.

No início dos anos de 1980 as preocupações com a gestão das organizações quanto ao fenômeno das TIC ganharam relevância. O seu impacto na Sociedade da Informação passava a se constituir como um novo problema que ameaçava a capacidade competitiva e a sobrevivência das próprias organizações. Dessa forma, surgiam novos questionamentos em termos organizacionais, o que levou a considerar que se fazia necessário enfocar em informações relevantes, tornando pertinente ao alinhamento estratégico das tecnologias de informação e comunicação com os objetivos organizacionais. Ao considerar a Filosofia da Informação abordada por Ilharco (2003), alinhar refere-se a submeter a nova tecnologia à estratégia organizacional. 
À medida que as potencialidades inovadoras das tecnologias são absorvidas pela sociedade proporciona-se novas possibilidades de produção, divulgação, inovação, comunicação, utilização e reutilização e de mudanças organizacionais, econômicas, culturais, educacionais e sociais, logo, faz-se entender que as TIC consistem em instrumentos que funcionam como apoio para a Sociedade da Informação, que possibilitam desenvolver ou organizar algo, constituído por meios que visam fins. Este entendimento instrumental da tecnologia tem prevalecido nas últimas décadas e tem motivado os questionamentos sobre os aspectos e implicações dos fenômenos da informação (REVOREDO, 2014; RODRIGUES, 2016).

Diante disso, Francelin e Pellegatti (2004) desenvolveram uma revisão de literatura que buscou analisar algumas questões sobre a informação no escopo da Ciência da Informação, objetivando propor a construção de estruturas conceituais, teóricas e epistemológicas múltiplas. As principais obras em que os autores se apoiaram foram do pesquisador Luciano Floridi. Ao longo da revisão de literatura, explanaram sobre os caminhos que a Filosofia da Informação já havia percorrido e o seu cenário atual. Como conclusão, os autores evidenciaram que a informação talvez não seja exclusiva da Ciência da Informação e ressaltaram para o fato de que ela possa ter um caráter ambíguo. Também alertaram que a Filosofia da Informação não se constitui como método da verdade, mas sim, da dúvida e do questionamento das verdades preestabelecidas.

Como um modo de exemplificar a afirmação feita por Francelin e Pellegatti (2004), são apresentados os trabalhos de Almeida (2008) e Rodrigues (2016) que abordam a informação em situações distintas, relacionando a informação com as TIC e explicitando as implicações que esta exerceu em cada contexto.

Rodrigues (2016) afirma que a Filosofia da Informação se configura como primogênita na reflexão e nos questionamentos de vários assuntos e fenômenos da sociedade contemporânea e relata as observações obtidas, a partir de análises de estudos relacionados as contribuições do acesso às novas TIC pelos povos indígenas da Amazônia brasileira, buscando compreender como se dá a relação entre pessoas de uma cultura tradicional e as redes sociais, por meio de dispositivos móveis de comunicação online que, gradativamente, são inseridos na cultura indígena. Como conclusão, o autor referenciado evidenciou que a tecnologia já faz parte do ambiente indígena há muito tempo e que participar das redes sociais é uma forma de difundir o patrimônio histórico de saberes indígenas e algumas tradições que este povo possui. 
A Filosofia da Informação também está presente na esfera educacional, assim como em tantas outras. Nessa esfera, Almeida (2008) relata que as TIC têm feito emergir uma discursividade que rompe com o paradigma sociocultural fundante dos sistemas educativos, referente a sua utilização como recursos que apoiam os processos de ensino e aprendizagem. Em seu estudo buscou identificar, descrever e explorar estratégias discursivas sobre o uso das TIC na educação. Ao longo do tex to apresentou e explorou as regras dos discursos que instituem as tecnologias de informação e comunicação na educação, na sequência abordou a informação e as suas consequências para esta área e evidenciou identidades docentes que emergem em tempos de tecnologias. A mesma autora compreende a educação como um processo emancipatório que tem sofrido alterações com a inclusão das TIC, influindo na migração do ensino presencial para o ciberespaço e instituindo pedagogias centradas no manuseio de distintas ferramentas informáticas.

O contexto apresentado sinaliza uma amplitude do potencial da ação das TIC na sociedade hodierna, o que possibilita definir padrões de socialização e de comportamento de forma a favorecer uma reorganização social, na qual, o papel da Filosofia da Informação passa a ser fundamental e precisa dar conta dos novos desafios que surgem em consequência da evolução tecnológica. Dentre esses desafios, destaca-se o tratamento de conceitos e fenômenos provenientes da revolução informacional e, como consequência, apoiar o desenvolvimento consciente e responsável da Sociedade da Informação.

\section{Considerações finais}

Este texto, embora embrionário, propicia reflexões acerca do campo científico da Informação, da Filosofia da informação e da Sociedade da informação. Diante do exposto, observou-se que a sociedade da informação tem proporcionado novas formas de pensar e agir em relação a informação e ao conhecimento, promovendo uma reorganização por meio de metodologias inovadoras, assim como, de uma base ontológica e epistemológica reformulada.

Os avanços tecnológicos forneceram a infraestrutura que possibilita um novo tipo de relacionamento, promoveu a interatividade e a interconectividade e reduziu de forma drástica o tempo necessário para a produção e para a disseminação de informações. Essas modificações alteraram a relação entre a informação e os indivíduos, o que ocasionou mudanças na estrutura da informação, no fluxo informacional e nos efeitos sofridos por ambos. 
Uma das consequências observada e resultante dessas modificações se refere a aproximação das áreas da Ciência da Informação e da Ciência da Computação. A Ciência da Informação mantém como foco a qualificação do acesso considerando as competências do indivíduo para que a apropriação da informação ocorra em sua plenitude. Por outro lado, a Ciência da Computação tem como perspectiva melhorar e ampliar os recursos tecnológicos que possibilitam armazenar e distribuir informações e proporcionam o acesso mais amplo à informação.

A informação tecnológica, no que lhe concerne, apresenta a capacidade de transformação da realidade, de modo mais acentuado. Essa capacidade foi demonstrada em pesquisas que abordam esta informação em áreas culturais e educacionais, entretanto, cabe ressaltar que esta mesma capacidade está presente em diversos segmentos na sociedade contemporânea.

Considerando esta pluralidade conceitual acerca do termo 'informação' e corroborando com Pellegrini e Vitorino (2018), conclui-se que a informação e a informação tecnológica necessitam de uma abordagem filosófica que possa contribuir para a área da Ciência da Informação no âmbito da Sociedade da Informação.

A Filosofia da Informação se refere a uma discussão filosófica inter-relacionada às questões afetas a informação, ou seja, é uma maneira de pensar a informação sob um viés filosófico. Também pode-se inferir que esta filosofia tem se consolidado como uma área de investigação autônoma que versa sobre questões emergentes da Sociedade da Informação e tem sido amplamente abordada na Ciência da Informação.

Em consideração a isso, é importante ressaltar os dois aspectos presentes no conceito da Filosofia da Informação destacados por Ilharco (2003). O primeiro aspecto se refere a investigação crítica da natureza conceitual e dos princípios baseados na informação. O segundo, aborda a elaboração de teorias e metodologias informacionais e computacionais, incluindo a aplicação dessas aos problemas filosóficos. Dessa maneira, este autor considera que a tecnologia da informação disponível a serviço da atividade intelectual do ser humano, estabelece as questões principais e centrais da Filosofia da Informação.

Nessa perspectiva, desperta a necessidade de reflexão sobre como a sociedade se comporta diante do progresso tecnológico. Os aparatos tecnológicos passaram a fazer parte do cotidiano, facilitando e dinamizando o acesso à informação e, consequentemente, a 
comunicação. Assim, a tecnologia passa a ser vista como possibilidade para resolver problemas e está presente nos variados aspectos da sociedade atual. Esta vasta presença reforça a necessidade de uma retomada do pensamento crítico e de uma conscientização ética em ambientes digitais, destacando assim a importância da Filosofia da Informação nos distintos contextos da Sociedade da Informação.

Por consequente, a Filosofia da Informação, assim como a sua relação com a informação e com a Sociedade da Informação tem sido discutida na esfera da Ciência da Informação de modo crescente, e a sua importância é relatada como promissora por autores da área. Entretanto, há ainda diversas lacunas a serem estudadas e respondidas e, diante do objetivo deste artigo, em que buscou-se compreender a Filosofia da Informação e sua relação com a sociedade contemporânea, despontaram questionamentos que carecem de aprofundamento e, portanto, de maior esforço científico.

Entre esses questionamentos, salienta-se a pertinente preocupação com o surgimento de problemas como a sobrecarga de informação e a falta de confiabilidade das informações produzidas e disseminadas, em especial destacando reflexões acerca de como esta sobrecarga interfere no desenvolvimento da Sociedade da Informação? Da mesma maneira, indaga-se como a confiabilidade ou a falta de confiabilidade das informações interfere no desenvolvimento da Sociedade da Informação?

Outro questionamento relevante se refere a informação ser considerada como elemento estrutural do mundo contemporâneo. Nessa situação, como podem os excluídos desse mundo tecnológico estabelecerem seus relacionamentos, adquirirem ou ampliarem conhecimentos e desenvolverem suas atividades nesta sociedade dita de informação?

Por fim, destaca-se o questionamento de Montoya-Mogollón e Madio (2018): seria esta uma Sociedade da Informação ou uma Sociedade Informacional mediada por recursos tecnológicos?

Com essas provocações, espera-se que as contribuições aqui abordadas, sirvam como estímulo para o desenvolvimento de novos estudos sobre a Filosofia da Informação, em seus vários aspectos disciplinares, interdisciplinares e transdisciplinares que, de alguma maneira, possam favorecer de fato o que se denomina de Sociedade da Informação. 


\section{Referências}

ALMEIDA, M. C. A. As tecnologias da informação e comunicação (TIC), os novos contextos de ensino-aprendizagem e a identidade profissional dos professores. Revista Brasileira de Estudos Pedagógicos, Brasília, v. 89, n. 221, p. 30-46, jan./abr. 2008. Disponível em: http://rbepold.inep.gov.br/index.php/rbep/article/view/723/699. Acesso em: 12 mar. 2021.

BARRETO, A. A. O tempo e o espaço da sociedade da informação no Brasil. Informação \& Informação, Londrina, v. 8, n. 1, p. 5-13, jan./jun. 2003. Disponível em: http://www.uel.br/revistas/uel//index.php/informacao/article/view/1707/1458. Acesso em: 5 maio 2021.

BORGES, M. A. G. A compreensão da sociedade da informação. Ciência da Informação, Brasília, v. 29, n. 3, p. 25-32, set./dez. 2000. Disponível em:

http://revista.ibict.br/ciinf/article/view/870/904. Acesso em: 12 mar. 2021.

BOTTENTUIT JÚNIOR, J. B.; COUTINHO, C. P. A educação a distância para a formação ao longo da vida na sociedade do conhecimento. In: BARCA, A. et al. (Eds.). Libro de actas do congreso internacional galego-portugués de psicopedagoxía. La Coruña: Universidade da Coruña, 2007. Disponível em:

http://repositorium.sdum.uminho.pt/bitstream/1822/7056/1/EAD.pdf. Acesso em: 12 mar. 2021.

CAPURRO, R.; HJØRLAND, B. O conceito de informação. Perspectivas em Ciência da Informação, Belo Horizonte, v. 12, n. 1, p. 148-207, jan./abr. 2007. Disponível em: http://portaldeperiodicos.eci.ufmg.br/index.php/pci/article/view/54/47. Acesso em: 12 mar. 2021.

CEZAR, K. G.; SUAIDEN, E. J. O impacto da sociedade da informação no processo de desenvolvimento. Informação \& Sociedade: Estudos, João Pessoa, v. 27, n. 3, p. 19-29, set./dez. 2017. Disponível em: https://periodicos.ufpb.br/ojs/index.php/ies/article/download/ 34305/18967. Acesso em: 19 jul. 2021.

FLORIDI, L. What is the philosophy of information? Metaphilosophy, Malden, v. 33, n. 1/2, p. 123-145, Jan. 2002. Disponível em: https://www.jstor.org/stable/24439320. Acesso em: 12 mar. 2021.

FLORIDI, L. Open problems in the philosophy of information. Metaphilosophy, v. 35, n. 4, p. 554-582, Jul. 2004. Disponível em: https://doi.org/10.1111/j.1467-9973.2004.00336.x. Acesso em: 12 mar. 2021.

FLORIDI, L. Semantic conceptions of information. In: ZALTA, Edward N. (ed.). The Stanford encyclopedia of philosophy (spring 2017 edition). 2017. Disponível em https://plato.stanford.edu/archives/spr2017/entries/informationsemantic/. Acesso em: 12 mar. 2021.

FLORIDI, Luciano. The philosophy of information. Oxford: Oxford University Press, 2011.

FLORIDI, L. Biblioteconomia e Ciência da informação (BCI) como filosofia da informação aplicada: uma reavaliação. InCID: Revista de Ciência da Informação e Documentação, Ribeirão Preto, v. 1, n. 2, p. 37-47, jul./dez. 2010b. Disponível em: https://www.revistas.usp.br/incid/article/view/42318/45989. Acesso em: 5 maio 2021. 
FLORIDI, L. Information: a very short introduction. Oxford: Oxford University Press, 2010c.

FRANCELIN, M. M.; PELLEGATTI, C. Filosofia da informação: reflexos e reflexões. Transinformação, Campinas, v. 16, n. 2, p. 123-132, maio/ago. 2004. Disponível em: https://www.scielo.br/pdf/tinf/v16n2/02.pdf. Acesso em: 12 mar. 2021.

FREITAS, Lídia Silva de. A memória polêmica da noção de sociedade da informação e sua relação com a área de informação. Informação \& Sociedade: Estudos, João Pessoa, V. 12, n.2, 2002. Disponível em https://brapci.inf.br/_repositorio/2010/11/pdf_dfa3bcd054_0013354 .pdf Acesso em: 19 jul. 2021.

ILHARCO, F. Filosofia da informação: uma introdução à informação como fundação da acção da comunidade e da decisão. Lisboa: Universidade Católica, 2003.

ILHARCO, F. Filosofia da informação: alguns problemas fundadores. In: SOPCOM, 3.; LUSOCOM, 6.; IBÉRICO, 2., 2005. Actas... [S.l.]: [S.n.], 2005. v. 2. Disponível em: http://docplayer.com.br/74386521-Filosofia-da-informacao-alguns-problemas-fundadoresfernando-ilharco-1.html. Acesso em: 12 mar. 2021.

LEITE, L. R. T.; MATOS, J. C. M. Zumbificação da informação: a desinformação e o caos informacional. Revista Brasileira de Biblioteconomia e Documentação, São Paulo, v. 13, n. esp., p. 2334-2349, 2017. Disponível em: https://rbbd.febab.org.br/rbbd/article/view/918/941. Acesso em: 12 mar. 2021.

LEITE, L. R. T. Confiabilidade informacional: a filosofia da informação e o desenvolvimento da leitura crítica no ambiente virtual. Dissertação (Mestrado) - Programa de Pós-graduação em Gestão da Informação, Universidade do Estado de Santa Catarina (UDESC), Centro de Ciências Humanas e da Educação, Florianópolis, 2018. Disponível em: http://www.bu.ufsc.br/teses/UDESC0036-D. Acesso em: 16 jul. 2021.

MONTOYA-MOGOLLÓN, J. B.; MADIO, T. C. C. Sociedade tecnológica da informação. In: ENCONTRO NACIONAL DE PESQUISA EM CIÊNCIA DA INFORMAÇÃO, 19., 2018, Londrina. Anais eletrônicos... Londrina: ANCIB; UEL, 2018. Disponível em: http://hdl.handle.net/20.500.11959/brapci/102258. Acesso em: 27 abr. 2021.

PELLEGRINI, E.; VITORINO, E. V. A dimensão ética da competência em informação sob a perspectiva da Filosofia. Perspectivas em Ciência da informação, Belo Horizonte, v. 23, n. 2, p. 117-133, out./dez. 2018. Disponível em: http://portaldeperiodicos.eci.ufmg.br/index.php/pci/article/view/2953/2072. Acesso em: 12 mar. 2021.

REVOREDO, T. M. A filosofia da informação no Brasil: uma representação dos artigos cinéticos produzidos entre os anos 1972 e 2013. In: ENCONTRO NACIONAL DE PESQUISA EM CIÊNCIA DA INFORMAÇÃO, 15., 2014, Belo Horizonte. Anais Eletrônico... Belo Horizonte: ANCIB; UFMG, 2014. Disponível em: http://hdl.handle.net/123456789/3082. Acesso em: 5 maio 2021.

REVOREDO, T. M. A filosofia da informação na Ciência da informação brasileira: uma análise da repercussão da teoria de Luciano Floridi. 2015. Dissertação (Mestrado) - Programa de Pós-graduação em Ciência da Informação, Universidade Federal de Pernambuco, Recife, 2015. Disponível em: 
https://repositorio.ufpe.br/bitstream/123456789/17213/1/DISSERTA\%c3\%87\%c3\%830\%20 T\%c3\%balio\%20de\%20Morais\%20Revoredo.pdf. Acesso em: 12 mar. 2021.

RIPOLL, L.; MATOS, J. C. M. Desinformação e informação semântica: a filosofia da informação e o pensamento de Luciano Floridi na contribuição à confiabilidade informacional. Em Questão, Porto Alegre, v. 26, n. 2, p. 211-232, maio/ago. 2020. Disponível em: https://seer.ufrgs.br/EmQuestao/article/view/90428/56062. Acesso em: 5 maio 2021.

RODRIGUES, A. Os ecossistemas comunicacionais e filosofia da informação: a relação da cultura indígena com as redes sociais. In: CONGRESSO DE CIÊNCIAS DA COMUNICAÇÃO NA REGIÃO NORTE, 15., 2016. Anais eletrônicos... Boa Vista: INTERCOM, 2016. 9 p. Disponível em:

https://www.portalintercom.org.br/anais/norte2016/resumos/R49-0597-1.pdf. Acesso em: 12 mar. 2021.

ROZA, R. H. Ciência da informação, tecnologia e sociedade. Biblos: Revista do Instituto de Ciências Humanas e da Informação, Rio Grande, v. 32, n. 2, p. 177-190, jul./dez. 2018. Disponível em: https://periodicos.furg.br/biblos/article/view/7546/5861. Acesso em: 5 maio 2021.

SALCEDO, D. A.; REVOREDO, T. M. O estado da arte da Filosofia da informação na Ciência da informação brasileira. DataGramaZero, Rio de Janeiro, v. 14, n. 6, p. 1-15, dez, 2013. Disponível em: https://brapci.inf.br/index.php/article/download/50775. Acesso em: 12 mar. 2021.

SANTOS, P. L. V. A. C.; CARVALHO, A. M. G. Sociedade da informação: avanços e retrocessos no acesso e no uso da informação. Informação \& Sociedade: Estudos, João Pessoa, p. 45-55, 2009.

SARACEVIC, T. Relevance: a review of and a framework for the thinking on the notion in information science. Journal of the American Society for Information Science, Hoboken, Nova Jersey, v. 26, n. 6, p. 321-343, Nov./Dec. 1975. Disponível em: https://doi.org/10.1002/asi.4630260604. Acesso em: 12 mar. 2021.

VIEIRA, E. M. F. Fluxo informacional como processo à construção de modelo de avaliação para implantação de cursos em educação a distância. 2006. 182f. Tese (Doutorado) - Programa de Pós-graduação em Engenharia e Gestão do Conhecimento, Universidade Federal de Santa Catarina, Florianópolis, 2006. Disponível em: https://repositorio.ufsc.br/xmlui/bitstream/handle/123456789/88291/233747.pdf?sequence=1 \&isAllowed=y. Acesso em: 12 mar. 2021.

WILKE, V. C. L. Filosofia e informação: dos muitos sentidos de informação e algumas abordagens filosóficas-contribuições para a epistemologia da informação. Informação Arquivística, Rio de Janeiro, v. 1, n. 1, p. 91-112, jul./dez. 2012. Disponível em: http://www.aaerj.org.br/ojs/index.php/informacaoarquivistica/article/view/7/6. Acesso em: 5 maio 2021. 